\title{
Strategic Efficiency. An Example using Data Envelopment Analysis in the Spanish Ceramic Tiles Industry.
}

Francisco Marco-Serrano ${ }^{1}$,

\section{University of Liverpool Online}

* francisco.marco-serrano@online.liverpool.ac.uk

\begin{abstract}
The strategic groups analysis, developed by Michael Porter [10] 11], is defined between the sectoral analysis and the individual competitors assessment. It allows to set groups of companies with similar strategies. Generally, a deep knowledge of the strategic characteristics of the companies is needed. Our proposal is focused on the public financial information extracted from the registered accounts. From this information, mixing the Data Envelopment Analysis based methodologies from Zhu [16] and Barr et al. [2], strategic groups are identified. For these aims, the 'strategic efficiency' concept is defined as the conjoint use of productive efficiency and (shareholder) value creation.
\end{abstract}

\section{Introduction}

The economic analysis of a sector involves not only knowledge about the dynamics of the environment in which it operates, or the establishment and analysis of individual results and behaviours at the sectoral level, which both require a deep subject matter expertise and involvement in the sector.

Moving between the aggregate level of a sector and the individual analysis of its companies, there is an intermediate level of analysis that is also of interest. This type of analysis is at which the competitive structure of the sector is established: the strategic groups.

It is of utmost importance to establish objectively the different groups that comprise a given sector, so that different methodologies have been proposed since the conception of the concept of 'strategic group'. Thus, in this article a methodological proposal is made using only companies public data. This proposal aims at using information that companies are more accustomed to analyse, financial data obtained from the public companies registry (eg 'Registro Mercantil' in Spain, or Companies House in the UK).

As an example, this proposal is demonstrated through the analysis of the Spanish ceramic tiles sector, an industry I was involved with at the beginning of my career; the sector is identified in the following section. Next, we define the concept of a strategic group and develop the methodology used for the identification of these ones, following with the analysis for the ceramics sector. Finally, we conclude with the most important points, as well as future ways of continuity of the research line. 


\section{Sector Identification}

This article analyses various aspects of the Spanish tile ceramic sector, understood as the industrial sector for the manufacture of ceramic type products for pavement and/or cladding. From an operational perspective, which allows us to articulate a better identification and subsequent classification of companies and workplaces within the sector, we use its statistical definition, according to the Spanish Statistical Classification of Economic Activities (CNAE 2009) [9].

The industrial activities analysed in this report are integrated under Section 23, manufacture of other non-metallic mineral products. Such section comprises the activities of manufacturing glass and glass products, ceramic products, tiles and products from baked clay, and cement and gypsum, from raw materials to finished goods. This section is completed with the cutting and finishing activities of stone and other mineral products.

In this research, we only include Subsection 2331, manufacture of ceramic tiles: wall and fireplace tiles, pieces for mosaics, non-refractory ceramics, and the manufacture of non-refractory ceramic tiles and paving stones.

\section{Strategic Groups}

The analysis of a productive sector requires the evaluation of macroeconomic data and its importance in the regional development. At the same time, microeconomic analysis, in which the analysis focuses on the economic and financial values of the organizations belonging to the analysed sector, is of paramount importance, too.

Halfway between the two scopes of analysis, we find what we call 'strategic groups', a concept developed by Michael Porter [10 [11. Through this concept we can evaluate the intra-sectoral dynamics at the level of strategic behaviour, which will allow us to simplify the business heterogeneity within the sector by reducing the number of strategic units on which to focus our attention. In fact, the definition of strategic group itself is related to the grouping of companies of the same sector that have an equal or similar strategy with respect to their strategic dimensions (read product specialisation, brand image, distribution channel, R\&D, pricing, etc), although a similar analysis can also be made through financial data.

The strategic groups are formed based on three basic characteristics: (1) strategic similarity; all companies in the group share common strategic features; (2) internal homogeneity/external heterogeneity; the common features among the companies of a group differentiate them from the companies outside it; (3) uniform response to threats and opportunities; with changes in the business environment, the companies of a group usually react in the same way. These characteristics will help us to identify direct competitors, and how they compete, evaluate possibilities for strategic group change, and identify opportunities and niche markets, as well as the existence of possible strategic problems.

In general, the contemporary analysis of strategic groups has been developed based on qualitative variables, as well as from the strategic characteristics; Flavian and Polo 8] identify a few dozens of variables in almost 20 different research works, in which various methodologies are used (bivariate, cluster analysis, factorial, logit, multidimensional scaling, and cognitive methodology), while Day et al. [5], in their review of the state of the art on strategic groups from the 1970s to the mid-1990s, note that the two most commonly used methodologies were cluster analysis and inspection.

In the specific case of the ceramic sector we find the works of Segura et al. [15], in which the segmentation methodology is the factorial analysis based on a series of qualitative variables that indicate the degree of priority given by the company (data 
were obtained by survey) to certain aspects such as efficiency, the development of new products, cost reduction, etc; in Segarra and Segura 14], however, it is used the information of previous studies, validating the groups identified by expert opinion, being the two classification variables used the product typology and the level of quality of the range.

In our research we use a different perspective, using variables obtained from the public financial accounts. Under this decision lies the assumption that financial results are a direct result of the strategic behaviour of a company, and that therefore we can group the different companies based on their accounting structure and annual results. This assumption is plausible, since the strategy depends on the executive and senior management of the company, who are themselves accountable to the owners (shareholders, investors) for the economic results of the company. However, according to the principle of equifinality [3], in its application to the business environment $[7]$ we can assume that different strategies materialized in different organizational configurations can lead to the same strategic results, So that companies categorized according to the methodology chosen as belonging to the same strategic group may have deployed different strategies and still have achieved the same strategic results. In other words, the classification achieved on the basis of this goal approach methodology does not have to coincide with classifications based on instrumental type variables. Moreover, the term 'strategic group' used in this paper is closer to a conception of grouping by results rather than by behaviour, as defined in the business literature.

\section{Methodology}

The indicators that are used to classify the different companies in the respective strategic groups are constructed from the economic concepts of 'productivity' and 'creation of value', following the proposal of Zhu [16], adapting the methodology to the characteristics of the companies analysed and to the available information. Therefore, the grouping will be made against the strategic results, instead of the strategic behaviours.

The other major difference between the conventional analysis of strategic groups and the evaluation used in this report is a methodological one. In order to find out the different strategic groups, a mathematical technique of identification of best practices called 'data envelopment analysis' (DEA) has been used.

In the seminal DEA model, efficiency is defined as a weighted sum of outputs to a weighted sum of inputs, where the weights structure is calculated using mathematical programming and it assumes constant returns to scale [4], with the possibility to calculate them considering variable returns to scale [1].

DEA has been used as a technique for identifying strategic groups previously in works such as Day et al. 6] [5], in an application to the brewing industry in the United States, or that of Prior and Surroca [12 [13], for the Spanish banking sector.

From this analysis, efficiency indices are derived from the business management process of transformation of resources into results, becoming a good single indicator to classify a company according to its 'strategic efficiency'.

To determine strategic best practice groups, formed by strategic leaders, we have used a multi-variable business performance model (the productivity and financial efficiency of companies is measured through various indicators), considered in two phases (see Figure 1).

In the first phase, the companies' ability to obtain income and profits, was analysed using their basic resources (number of employees, total assets and shareholders funds). This is the phase we call 'productivity factor'. In the second phase we analysed how 


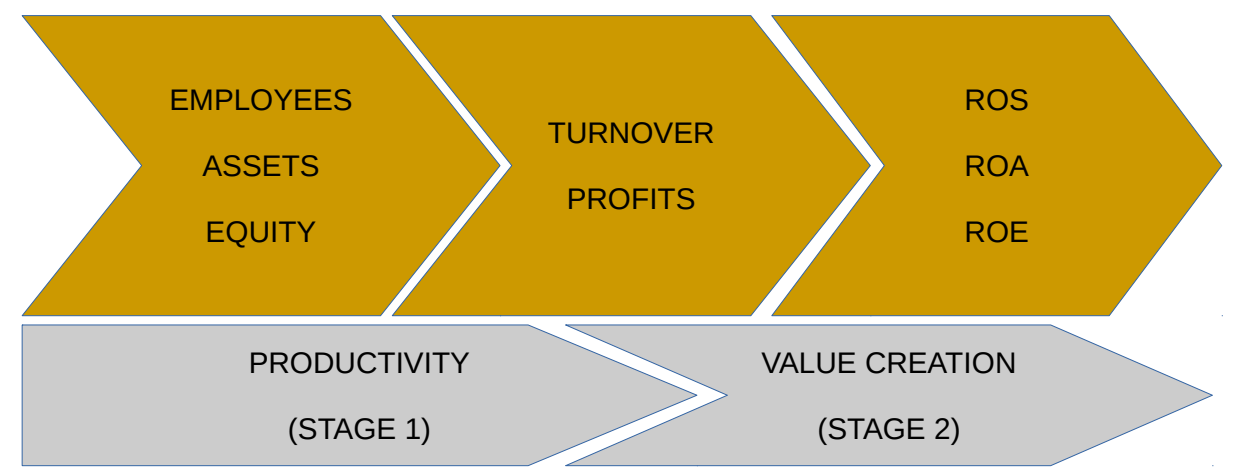

Figure 1. Conceptual Model. Adapted from Zhu 16 .

companies are able to obtain maximum returns, considering that they have obtained a positive net income and profits. It is the 'creation of value' factor.

From the evaluations of the companies following this scheme in two phases, we will obtain the values of productivity efficiencies and creation of value, which will allow us to classify the companies according to their strategic efficiency, defined as the capacity to extract the maximum yield to the basic business resources: employment, assets, and equity.

Performance is measured through three indicators widely used in economic and financial analysis: ROS (Return On Sales), ROA (Return On Assets), and ROE (Return On Equity).

Finally, we consider that there are variable returns to scale in the conversion of resources into results; That is, we incorporate to the analysis the assumption that there are variations in the results derived from the size of the company.

Thus, through the methodology based on the data analysis, the strategic similarity will be sought, the first basic characteristic of the strategic groups; By contrasting the hypotheses of the resulting groups, the second characteristic, internal homogeneity / external heterogeneity will be analysed; For the analysis of the last characteristic, a dynamic analysis would be necessary, although we understand that by means of the conformation of the strategic groups based on both chosen factors (productivity and value creation) this characteristic is included in the base methodology.

The calculation of the efficiencies has been done through a stepwise process proposed by Barr et al 22, that allows to obtain a classification of the companies based on the efficiency values obtained, similar to the microeconomic concept of isoquants. In an iterative process, the companies that arise as the most efficient are taken out of the dataset and the efficiency analysis repeated with the new filtered data, then obtaining different tiers of efficiencies. 


\section{Data}

The non-consolidated Annual Accounts of 235 companies of the Spanish ceramic tiles sector were collected for the financial year 2008, year when the subprime mortgage crisis hadn't hit the economy yet. According to data from the Central Directory of Companies of the INE (DIRCE), these represent $61.4 \%$ of the total of companies with employees in the sector analysed.

A filtering process has been carried out in which the entities in a bankruptcy or liquidation, those with negative equity, and those that recorded losses in their ordinary results have been eliminated from the analysis. After this filtering, the number of companies analysed was 105 , whose average values and standard deviation of the variables to be used in the analysis can be seen in Table 1.

It can be noticed the high variability existing, due to the wide variety of business sizes in the sector: $21.9 \%$ of the companies in the sample have up to 10 employees, with $36.2 \%$ employing between 50 and 250 people.

Table 1. Resources-Results.

\begin{tabular}{|c|l|r|r|}
\hline \multicolumn{2}{|c|}{ Variable } & Mean & Std.Dev. \\
\hline $\mathrm{n}$ & Companies (total) & 105 & - \\
\hline EMP & Employees & 70 & 106 \\
\hline ASS & Total Assets (thou EUR) & 18,888 & 36,183 \\
\hline EQU & Equity (thou EUR) & 9,284 & 18,273 \\
\hline TUR & Turnover (thou EUR) & 13,069 & 22,729 \\
\hline PRO & Profits (thou EUR) & 603 & 1,295 \\
\hline ROS & Return on Sales (\%) & 7.40 & 17.36 \\
\hline ROA & Return on Assets (\%) & 3.16 & 3.43 \\
\hline ROE & Return on Equity (\%) & 9.03 & 12.21 \\
\hline \multicolumn{3}{|c|}{ Own source from Spanish Companies House. }
\end{tabular}

\section{Results}

For each subsector, four clusters or levels were obtained for the first factor, and five levels for the second; within each level, all firms can be considered on an equal baseline in terms of efficiency in the conversion of resources into results, and more efficient than the companies of lower groups (eg a company in the second group is more efficient than another of the third).

In addition, we have calculated the mean values for efficiency within each cluster, which would allow us to estimate the potential for improvement of a company in terms of results, targeting each group. The following tables show the average efficiency data for each group and the percentage of companies that make up each reference group, for the productivity factor and the value creation factor.

Table 2 invites us to reflect on the structure of efficiency in achieving the goals of productivity and value creation of ceramic manufacturing companies. For example, we can infer that a company in the fourth group could reduce, on average, its inefficiency in creating value by more than $50 \%$ if it managed to reach the third group, from $494 \%$ to only $250 \%$. Similarly, if this same company were included in group 3 in terms of productivity factor and managed to improve it to group 2, it would have on average achieved a reduction in its productivity inefficiency by 10 percentage points (from $168 \%$ to $158 \%$ ). Since these types of indicators are constructed from a methodology of comparison between companies, where the best practices are those that establish the degree of inefficiency, the transition from an inferior strategic group to a superior one 
Table 2. Efficiencies per Level.

\begin{tabular}{|c|c|c|c|c|}
\hline \multirow{2}{*}{ Level } & \multicolumn{2}{|c|}{ Productivity Factor } & \multicolumn{2}{c|}{ Value Creation } \\
\cline { 2 - 5 } & Companies (\%) & Avg.Eff. & Companies (\%) & Avg.Eff. \\
\hline 1 & $16 \%$ & $100 \%$ & $12 \%$ & $100 \%$ \\
\hline 2 & $30 \%$ & $158 \%$ & $12 \%$ & $171 \%$ \\
\hline 3 & $26 \%$ & $168 \%$ & $12 \%$ & $250 \%$ \\
\hline 4 & $17 \%$ & $198 \%$ & $14 \%$ & $494 \%$ \\
\hline 5 & - & - & $12 \%$ & $577 \%$ \\
\hline Rest & $11 \%$ & $238 \%$ & $38 \%$ & $1560 \%$ \\
\hline \hline Total & $100 \%$ & $176 \%$ & $100 \%$ & $805 \%$ \\
\hline
\end{tabular}

implies the reduction of the competitive advantages of the competitors against the company analysed, either in terms of productivity or value creation, depending on the factor we are analysing. This possibility, however, clashes with one of the characteristics that allows the identification and classification of a group of companies as a strategic group: mobility barriers, which hinder inter-group change.

Table 3. Strategic Groups Distribution.

\begin{tabular}{|c|c|c|c|c|c|c|c|c|}
\hline \multirow{2}{*}{\multicolumn{2}{|c|}{ Level }} & \multicolumn{6}{|c|}{ Value Creation } & \multirow{2}{*}{ Total } \\
\hline & & 1 & 2 & 3 & 4 & 5 & Rest & \\
\hline \multirow{5}{*}{ 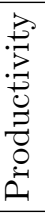 } & 1 & $3.8 \%$ & $5.7 \%$ & $1.9 \%$ & $1.0 \%$ & - & $3.8 \%$ & $16.2 \%$ \\
\hline & 2 & $4.8 \%$ & $3.8 \%$ & $4.8 \%$ & $4.8 \%$ & $2.9 \%$ & $8.6 \%$ & $29.6 \%$ \\
\hline & 3 & $1.9 \%$ & $1.9 \%$ & $3.8 \%$ & $2.9 \%$ & $4.8 \%$ & $10.5 \%$ & $25.8 \%$ \\
\hline & 4 & $1.0 \%$ & $1.0 \%$ & $1.0 \%$ & $4.8 \%$ & - & $9.5 \%$ & $17.2 \%$ \\
\hline & Rest & $1.0 \%$ & - & - & $1.0 \%$ & $3.8 \%$ & $5.7 \%$ & $11.4 \%$ \\
\hline \multicolumn{2}{|c|}{ Total } & $12.4 \%$ & $12.4 \%$ & $11.4 \%$ & $14.4 \%$ & $11.5 \%$ & $38.1 \%$ & $100.0 \%$ \\
\hline
\end{tabular}

Although the most interesting analysis is the result of the pooling of the results of both indicators. By constructing a table that combines the results obtained in the indicator of productive efficiency and that of efficiency in the creation of value, we obtain the different strategic groups in terms of the concept of strategic efficiency.

Table 4 shows the different groups that emerged from the analysis and the percentage of companies that make them up, indicating in turn, in those significant groups, the average values of the inputs and products of the companies that form part of the Group.

In turn, we can verify how there is no correlation between both factors; the Pearson correlation takes value $-0.0434(\mathrm{p}$-value $=0.6635)$, while the Spearman stat takes value 0.0703 (p-value=0.4801), and the Tau-b $0.0529(\mathrm{p}$-value=0.4366) . Then, we can assert the use of information from both factors to allocate each company in its group is not redundant.

Moreover, if we analyse the groups from Table 4 by testing the independence between the two factors, given the categories 'group 1' to 'group 4', we cannot reject this hypothesis at a level of significance of $5 \%(\operatorname{chi}-\operatorname{squared}(9)=11.04, \mathrm{p}$-value $=0.2733)$. Note that for the application of the chi-square test the 'group 5' and the 'Rest' categories (absolutely inefficient firms) have not been considered in the analysis.

Finally, in order to validate the discriminant capacity of the methodology, a two-way ANOVA model is applied, which contrasts the capacity of the factor productivity and the factor of creation of value to explain the differences in the mean values of the variables used in the analysis. In Table 5 the results of a ranked 2-way ANOVA are shown, including the interaction. 
Table 4. Strategic Groups: Variable Mean Values.

Values shown only for groups with more than 3 companies.

\begin{tabular}{|c|c|c|c|c|c|c|c|}
\hline \multirow{2}{*}{\multicolumn{3}{|c|}{ Level }} & \multicolumn{5}{|c|}{ Value Creation } \\
\hline & & & $1(n=12)$ & $2(\mathrm{n}=13)$ & $3(\mathrm{n}=12)$ & $4(n=14)$ & $5(n=5)$ \\
\hline \multirow{36}{*}{ 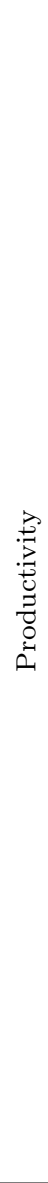 } & & $\mathrm{n}$ & 4 & 6 & 2 & 1 & - \\
\hline & & EMP & 35 & 33 & - & - & - \\
\hline & & ASS & 11,351 & 4,179 & - & - & - \\
\hline & & EQU & 8,043 & 832 & - & - & - \\
\hline & $1(\mathrm{n}=10)$ & TUR & 12,541 & 5,892 & - & - & - \\
\hline & & $\mathrm{PRO}$ & 2,032 & 184 & - & - & - \\
\hline & & ROS & 6.65 & 5.29 & - & - & - \\
\hline & & ROA & 8.54 & 2.68 & - & - & - \\
\hline & & ROE & 53.98 & 24.50 & - & - & - \\
\hline & & $\mathrm{n}$ & 5 & 4 & 5 & 5 & - \\
\hline & & EMP & 26 & 39 & 78 & 34 & - \\
\hline & & ASS & 4,829 & 16,537 & 20,025 & 9,477 & - \\
\hline & & EQU & 3,601 & 9,264 & 11,104 & 6,745 & - \\
\hline & $2(\mathrm{n}=19)$ & TUR & 4,028 & 7,414 & 15,795 & 5,846 & - \\
\hline & & PRO & 675 & 174 & 1,779 & 616 & - \\
\hline & & ROS & 7.75 & 1.57 & 6.26 & 8.56 & - \\
\hline & & ROA & 6.06 & 1.17 & 5.90 & 4.79 & - \\
\hline & & $\mathrm{ROE}$ & 13.03 & 1.51 & 13.61 & 11.57 & - \\
\hline & & $\mathrm{n}$ & 2 & 2 & 4 & 3 & 5 \\
\hline & & EMP & - & - & 10 & - & 61 \\
\hline & & ASS & - & - & 868 & - & 13,918 \\
\hline & & EQU & - & - & 392 & - & 11,090 \\
\hline & $3(\mathrm{n}=9)$ & TUR & - & - & 717 & - & 8,397 \\
\hline & & PRO & - & - & 12 & - & 629 \\
\hline & & ROS & - & - & 1.55 & - & 6.22 \\
\hline & & ROA & - & - & 1.19 & - & 4.51 \\
\hline & & $\mathrm{ROE}$ & - & - & 3.11 & - & 8.11 \\
\hline & & $\mathrm{n}$ & 1 & 1 & 1 & 5 & - \\
\hline & & EMP & - & - & - & 30 & - \\
\hline & & ASS & - & - & - & 2,746 & - \\
\hline & & EQU & - & - & - & 1,511 & - \\
\hline & $4(\mathrm{n}=5)$ & TUR & - & - & - & 2,220 & - \\
\hline & & PRO & - & - & - & 105 & - \\
\hline & & ROS & - & - & - & 4.12 & - \\
\hline & & ROA & - & - & - & 2.86 & - \\
\hline & & ROE & - & - & - & 4.97 & - \\
\hline
\end{tabular}

As can be seen from Table 5, the only variable whose differences account for both factors is ROE, whereas in ROS it is the 'value creation' factor that can be attributed to differentiation characteristics. This suggests that the identification of strategic groups, and possibly their gestation, is closely linked to longer-term results, with productivity and value creation being realised in ROE; For its part, in the short term the creation of value would be represented by the return on sales (ROS).

\section{Conclusion}

The use of Data Enveloping Analysis according to the proposals of Zhu [16] and Barr et al. 2] has been used to estimate the structure of strategic groups in the Spanish ceramic tiles sector.

Based on the concept of strategic efficiency, and through the use of data obtained from the Spanish Companies House, different strategic groups have been obtained based on the productivity of companies and their capacity to create shareholder value.

Both factors of grouping are independent and allow to discriminate between the different strategic groups at least for the variable 'financial profitability' (ROE). 
Table 5. Two-way ANOVA.

\begin{tabular}{|c|c|c|c|}
\hline \multirow{2}{*}{$\begin{array}{c}\text { F-stat } \\
\text { p-value }\end{array}$} & \multicolumn{3}{|c|}{ Factor } \\
\cline { 2 - 4 } EMP & Productivity & Value Creation & Interaction \\
& 0.9645 & 0.1714 & 0.3627 \\
\multirow{2}{*}{ ASS } & 1.0287 & 0.9150 & 0.9451 \\
\hline \multirow{2}{*}{ EQU } & 0.3918 & 0.2773 & 0.5348 \\
& 0.7413 & 0.8414 & 0.8391 \\
\hline \multirow{2}{*}{ TURN } & 0.5346 & 0.8193 & 0.6496 \\
& 1.2095 & 0.1988 & 0.7472 \\
\hline \multirow{2}{*}{ PRO } & 0.3206 & 0.8965 & 0.9447 \\
& 0.9044 & 0.9290 & 0.3609 \\
\multirow{2}{*}{ ROS } & 1.3550 & 0.4370 & 0.9460 \\
& 0.2730 & 3.9099 & 3.9819 \\
\multirow{2}{*}{ ROA } & 1.7868 & $0.0168^{* *}$ & $0.0015^{* *}$ \\
\hline \multirow{2}{*}{ ROE } & 0.1677 & 0.8664 & 0.8823 \\
& 16.8078 & 0.4677 & 0.5501 \\
\hline \multirow{4}{*}{$* .0000^{* * *}$} & $0.0082^{* * *}$ & $0.0093^{* * *}$ \\
\hline
\end{tabular}

This methodology has the advantage of not needing very detailed information of the companies to classify them strategically; however, the capacity for discernment between some groups and others is limited to a single variable: ROE. On the other hand, rests on the assumption that financial variables are the reflection of strategic decisions.

Future research should be aimed at comparing the validity of the methodology by comparing the results with other techniques, as well as obtaining a method that allows the self-allocation of a company in its respective strategic group or peer group of good practices in terms of strategic efficiency. Further, the dynamic properties of the method should be tested, too.

\section{References}

1. R. Banker, A. Charnes, and W. Cooper. Some models for estimating technical and scale inefficiencies in data envelopment analysis. Management Science, 30:1078-1092, 1984.

2. R. Barr, M. Durchholz, and L. Seiford. Peeling the dea onion: Layering and rank-ordering dmus using tiered dea. Southern Methodist University Technical Report, 1994/2000.

3. L. v. Bertalanffy. General Systems Theory: Foundations, Development. New York: George Braziller, 1968.

4. A. Charnes, W. Cooper, and E. Rhodes. Measuring the efficiency of decision making units. European Journal of Operational Research, 2:429-444, 1978.

5. D. Day, A. Lewin, and H. Li. Strategic leaders or strategic groups: A longitudinal data envelopment analysis of the u.s. brewing industry. European Journal of Operational Research, 80:619-638, 1995. 
6. D. Day, A. Lewin, H. Li, and R. Salazar. Strategic Leaders in the U.S Brewing Industry: A Longitudinal Analysis of Outliers. Boston/Dordrecht/London: Kluwer Academic Publishers, 1994.

7. D. Doty, W. Glick, and G. Huber. Fit, equifinality, and organizational effectiveness: A test of two configurational theories. Academy of Management Journal, 36(3):1196-1250, 1993.

8. C. Flavian and Y. Polo. Hacia la homogeneización de criterios en las investigaciones de grupos estratégicos. Cuadernos de Economía y Dirección de la Empresa, 3:9-28, 1999.

9. INE. CNAE 2009. 2010.

10. M. Porter. The structure within industries and companies' performance. Review of Economics and Statistics, 6(1):214-227, 1979.

11. M. Porter. Competitive Strategy. Free Press, 1980.

12. D. Prior and J. Surroca. Modelo para la identificación de grupos estratégicos basado en el análisis envolvente de datos: Aplicación al sector bancario español. Universitat Autònoma de Barcelona, Documents de Treball, 2001/2, 2001.

13. D. Prior and J. Surroca. Strategic groups based on marginal rates: An application to the spanish banking industry. European Journal of Operational Research, 170(1):293-314, 2001.

14. M. Segarra and B. Segura. Cómo aplicar un modelo de análisis competitivo en el sector cerámico valenciano. X Congreso de Ingeniería de Organización, Valencia, 7 y 8 de Septiembre de 2006. Mimeo, 2006.

15. B. Segura, E. Vallada, C. Maroto, and R. Ruiz. Análisis del sistema de operaciones en empresas del sector cerámico español. Boletín de la Sociedad Española de Cerámica y Vidrio, 43:929-932, 2004.

16. J. Zhu. Multi-factor performance measure model with an application to fortune 500 companies. European Journal of Operational Research, 123:105-124, 2000. 